\title{
Covid-19 Desnuda As Contradições Da República Federativa Brasileira: A Dificuldade De Legitimar A Tomada De Decisão E A Proposta Da Instituição Do Comum
}

\author{
Gabriel Scudeller de Souza * \\ Centro Universitário Eurípides de Marília, Programa de Pós-Graduação em Direito, Marília-SP, Brasil. \\ iD https://orcid.org/0000-0002-7502-8863 \\ Vivianne Rigoldi \\ Centro Universitário Eurípides de Marília, Programa de Pós-Graduação em Direito, Marília-SP, Brasil.
}

iD https://orcid.org/oooo-0002-7257-3460

Resumo: O mundo em 2020 foi assomado por um novo coronavírus que se alastrou por diversos países e trouxe problemas de saúde e óbitos. Decretou-se a pandemia. A alta contaminação é o problema, diante do fato de colapsar os sistemas de saúde. A principal medida defendida é o isolamento social, com o intuito de achatar a curva de contágio. No Brasil, os entes federativos não defendem as mesmas propostas e contribuem para o agravamento da crise. Demonstra-se que a dificuldade do sistema pátrio em lidar com a crise desnuda o problema da tomada de decisão. Pensa-se, nesse cenário, em recorrer ao Poder Judiciário para que este aprecie acerca da defesa dos direitos humanos fundamentais frente às políticas públicas estatais. Ocorre que o processo judicial, embora uma alternativa, demanda o respeito a procedimentos processuais, o que pode não ser eficiente para uma decisão de urgência. Assim, tendo em vista os ensinamentos acerca do pluralismo jurídico, bem como à luz de um sistema mais participativo e deliberativo, postula-se por um novo centro de decisão, não centralizador e mais democrático, identificado como princípio do comum. Pelo método dedutivo, com consultas bibliográficas a artigos científicos, busca-se compreender tais questões sociais, agora desnudadas frente à Covid-19.

Palavras-chave: Pluralismo jurídico. Tomada de decisão. Pandemia. Covid-19. Comum.

* Mestrando em Direito e Estado na Era Digital no Centro Universitário Eurípides de Marília (PPGD/Univem). E-mail: gabrielscudeller2@gmail.com

** Doutora em Direito. Docente do Mestrado em Direito e do Curso de Graduação em Direito do Centro Universitário Eurípides de Marília. E-mail: rigoldi@univem.edu.br

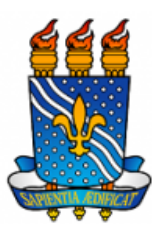

UNIVERSIDADE FEDERAL DA PARAÍBA

Programa de Pós-Graduação em Ciências Jurídicas

DOI: https://doi.org/10.22478/ufpb.1678-2593.2021v20n43.53647 


\title{
Covid-19 Desnuda As Contradições Da República Federativa Brasileira: A Dificuldade De Legitimar A Tomada De Decisão E A Proposta Da Instituição Do Comum
}

\author{
Gabriel Scudeller de Souza
}

Vivianne Rigoldi

\section{INTRODUÇÃO}

No ano de 2020 o mundo foi assomado por um novo coronavírus, chamado pela Organização Mundial da Saúde - OMS ${ }^{1}$ de "Covid-19", que desestabilizou as estruturas dos países, sem que se soubesse contra o que se lutava. Após meses de grandes perdas, começam-se a apresentar alternativas na tentativa de controle e contenção de danos, na expectativa de que uma nova vacina ${ }^{2}$ e um novo medicamento possam surgir.

A principal medida que demonstrou ser mais eficaz contra os avanços do vírus é o isolamento social, ou seja, a permanência dos indivíduos em casa, sem contato físico com outras pessoas para evitar contaminações e, consequentemente, a sobrecarga do sistema de saúde.

\footnotetext{
${ }^{1}$ Organização Mundial da Saúde - OMS. O artigo utilizará apenas a sigla OMS daqui para frente. Acesso em 08.04.2020: https://www.who.int/es/.

2 Diversos estudos estão em desenvolvimento, inclusive em fase final de testes, para aplicação de vacinas contra a Covid-19. Neste sentido, ver Coronavirus disease (COVID-19): Vaccines (who.int), acesso em 04.12.2020.
} 
No Brasil, embora os percentuais de contaminação e recuperação da doença sejam promissores, 3 se não houver medida de achatamento da curva de contaminação os leitos disponíveis nos hospitais não serão suficientes para o tratamento dos casos considerados graves. Em síntese: o sistema de saúde brasileiro não suportará a demanda e deixará de prestar o atendimento necessário.

O Poder Judiciário é uma alternativa para controle das decisões dos demais poderes constituídos. Porém, será que esse é o melhor campo para apostar na salvaguarda dos direitos humanos fundamentais? Momentos agudos como o que vivemos denotam que a estrutura organizacional-administrativa do Estado encontra limites que impedem o reconhecimento de sujeitos de direitos.

Há, na prática política - encontrando repercussão no cotidiano - uma narrativa baseada na nova racionalidade do mundo, qual seja o pensamento neoliberal, que toma conta de subjetividades e depende do Estado interventor para satisfação de seus interesses, afastando-se do liberalismo clássico.

Dessa forma, questiona-se: a centralidade da decisão é, nos tempos pós-modernos de democracias complexas, a melhor opção para os ditames da sociedade plural?

Inicia-se ressaltando a importância da democracia, com sua latência de produção de novos sujeitos e novos direitos, e dos limites constitucionalmente impostos, que servem de salvaguarda das próprias minorias que merecem ser ouvidas. Passa-se à análise da postura do Poder Judiciário que, por meio da jurisdição constitucional, pode se debruçar sobre campos políticos dos demais Poderes, à luz da satisfação dos direitos humanos fundamentais. Porém, questiona-se se esse caminho é suficiente para a promulgação da liberdade e proteção dos sujeitos de direitos, especialmente à luz dos limites procedimentais e interpretativos existentes, apresentando-

3 A informação foi retirada do site da OMS: https://www.who.int/es/emergencies/diseases/novel-coronavirus-2019/advicefor-public/q-a-coronaviruses, acesso em 08.04.2020. 
se, por fim, proposta de formação de base decisória a partir da produção do comum.

Vale-se, para tanto, como metodologia de pesquisa, do método dedutivo, com emprego da técnica de pesquisa bibliográfica, consultando artigos científicos e dissertações sobre o tema em comento, com o fito de propiciar, ao final e sem a pretensão de esgotar o assunto, um caminho seguro na manutenção dos direitos humanos fundamentais.

\section{PODER CONSTITUINTE E PODERES CONSTITUÍdOS. DEMOCRACIA E CONSTITUCIONALISMO: O INTERESSE DO POVO, E NÃo DOS GOVERNANTES, DEVE FIXAR O LIMITE DO DEMOCRÁTICO}

Um dos paradoxos que se apresenta para a teoria do direito constitucional é o entrechoque, de um lado, da democracia e, de outro, do constitucionalismo. Esse conflito pode ser melhor explicitado a partir das noções de soberania e poder constituinte, respectivamente.

[...] conciliar democracia e constitucionalismo é uma tarefa tão complexa quanto problemática. Se a democracia significa o povo decidindo as questões politicamente relevantes da sua comunidade, isso inclui os conteúdos da constituição de um país, isto é, as normas que organizam as instituições do governo e estabelecem limites aos respectivos poderes governamentais. Entretanto, se o constitucionalismo significa limites à soberania popular, então alguns conteúdos da Constituição - Law of lawmaking - devem permanecer fora do alcance da decisão majoritária ou das deliberações democráticas. Eis o paradoxo que marca a democracia constitucional (CHUEIRI; GODOY, 2010, p.160).

No tocante à soberania à luz da Constituição da República Federativa do Brasil de 1988, sua titularidade é ocupada pelo povo (art. $1^{\circ}$, I e parágrafo único), cabendo a este estabelecer as legislações e os referentes a serem seguidos pela República, autoimpondo-se normas e exigindo seu respeito (GARGARELLA, 1996). A Constituição é, portanto, fruto das deliberações constituintes da sociedade, devendo 
ser preservada como norte dos objetivos político-jurídicos de uma nação, vez que retrata essa mesma soberania popular, pelo chamado poder constituinte. Aqui há o elo entre os temas: democracia/soberania popular e constitucionalismo/poder constituinte.

A própria ideia de soberania surgiu de forma centralizadora e estática, na figura do rei soberano, que se colocava como o formulador e executor das normas, porém, sem que a elas se submetesse. Uma soberania absoluta e perpétua, compromissada com a primazia do comando coercitivo, de formato estatista, repressor, hierárquico e unitário (BODIN, 1576). Para Foucault (1990, p.85), tratava-se de um modelo caracterizado como "antienergia", ou seja, "um poder que somente tem a força negativa ao seu lado, um poder de dizer não; sem condições de produzir, capaz somente de impor limites".

Ocorre que a ideia de soberania no campo democrático destoa do paradigma monárquico acima retratado, uma vez que há a presença central do povo ocupando o local do rei, invertendo-se a autoridade política.

\begin{abstract}
A soberania muda de mãos, mas permanece essencialmente a mesma. Dessa maneira, o discurso do comando reduz a moderna democracia a uma instituição centralizada de poder coercitivo. A doutrina do Estadonação é uma narrativa acerca da democratização gradual do absolutismo da soberania monárquica (KALYVAS, 2013, p.40).
\end{abstract}

Nesse ponto surge a importante história política do poder constituinte, que trata contrariamente a essa narrativa do comando e da sujeição (NEGRI, 2002). Segundo Chueri e Godoy (2010, p. 161)

[...] para a ciência do direito, o poder constituinte é tradicionalmente a fonte da qual a nova ordem constitucional brota. É o poder de fazer a nova Constituição, da qual os poderes constituídos adquirem a sua estrutura. Desta perspectiva, o poder constituinte instala uma ordem jurídico-constitucional totalmente nova 
A teoria do poder constituinte surgiu, ainda com um ideal preso à nação, com a obra $A$ constituinte burguesa - que é o Terceiro Estado?, de Joseph Sieyés, trazendo a ideia de um poder anterior à Constituição, ilimitado e autônomo, incondicional e não vinculado, ou seja

[...] a Constituição pressupõe, antes de tudo, um poder constituinte, representante da soberania popular. Ou seja, os poderes resultantes da Constituição estão e são submissos a um poder constituinte anterior, a vontade soberana popular, e, portanto, tal poder não estaria vinculado a nada mais a não ser a sua própria vontade (SIEYÉS, 1997, p. 117).

Antonio Negri (2002) trata do poder constituinte como força onipotente e expansiva, produtora de normas constitucionais, e também o considera como um sujeito dessa produção, de forma que "qualificar constitucional e juridicamente o poder constituinte não será simplesmente produzir normas constitucionais e estruturar poderes constituídos, mas, sobretudo, ordenar o poder constituinte enquanto sujeito, a regular a política democrática” (NEGRI, 2002, p.8)4. O autor apresenta uma questão existente na própria ideia de poder constituinte, qual seja a contradição entre sua força produtora e seu produto. Em outras palavras, o potencial produtor de fundar o direito é oposto à própria produção do direito, já que a latência do poder constituinte é de produção. Tal percepção se afigura, também, na problemática da ideia de que a democracia é resistente à constitucionalização; a potência democrática é diversa do direito posto.

[...] a democracia é a teoria do governo absoluto, ao passo que o constitucionalismo é a teoria do governo limitado,

\footnotetext{
4 A proposta de Negri e Hardt aponta para problemas na aplicação do conceito de soberania clássico, diante da possibilidade de instituição de uma democracia absoluta, a partir das trocas de cooperação e comunicação atualmente permitidas a partir de uma biopolítica nunca antes proporcionada. Assim, rompe-se com o poder soberano centralizador - do Império (2002) - e permite-se a produção, em comum, do comum pela multidão. Laval e Dardot também questionarão o poder soberano, apresentando propostas para uma nova razão do mundo, também a partir do comum.
} 
da democracia limitada. O poder constituinte, sob a ótica jurídica, é a fonte de produção das normas constitucionais. Paradoxalmente, é um poder onipotente, que surge do nada e organiza todo o direito. No entanto, deve ser temporalmente limitado, encerrado em uma factualidade (...) a Constituição, criada pelo poder constituinte e para a democracia, mostra-se como obstáculo do próprio poder constituinte e da própria democracia (da soberania popular) (NEGRI, 2002, p. 07-09).

Em síntese, o poder constituinte cria o direito e define o modelo democrático - constitucionalismo - e, a partir de então, estes acabam por limitar sua própria latência. Aquele é tido por absoluto e, quando de sua produção, passa a ser limitado pelos poderes constituídos. Aparentemente pode-se pensar que esse conflito existente entre a democracia e o constitucionalismo possa ser prejudicial ou insuperável para o Estado Democrático de Direito, mas não necessariamente.

Lefort (1981) entende a democracia como um processo que se dá em constante reinvenção de direitos, trazendo para o cenário a característica do conflito, motor propulsor de avanços sociais humanitários, razão pela qual não merece ser erradicado. No mesmo caminho, Foucault (2019) admite a força produtiva do poder, um poder positivo que produz relações e interações sociais, produz subjetividade.

[é preciso] explorar os recursos de liberdade e de criatividade nos quais se abebera uma experiência que acolhe os efeitos da divisão; resistir à tentação de trocar o presente pelo futuro; fazer o esforço ao contrário para ler no presente as linhas da sorte indicadas com a defesa dos direitos adquiridos e a reivindicação dos direitos novos, aprendendo a distingui-los do que é apenas satisfação de interesses (LEFORT, 1981, p.69).

Essa tensão permanente entre o poder constituinte e os poderes constituídos se dá, justamente, pela posição democrática assumida pelas sociedades modernas. Tal constatação não é prejudicial ao consenso social, permite o refrescar das ideias e a promoção da pluralidade, de modo a preservar os padrões mínimos estabelecidos pelo constitucionalismo. 
Trata-se, assim, de um poder latente e permanente, que denota o valor epistêmico da democracia e requer a consideração de interesses expressados durante tempos e espaços históricos, presentes nas manifestações - constituintes - do poder popular, preservando a convenção constitucional, mantendo o impulso constituinte (NINO, 2003). São acontecimentos, dentro de um processo histórico de reconhecimento de poderes e vontades que forjam o constitucionalismo, pregando respeito aos direitos nele abarcados e preservando a democracia socialmente latente.

[...] no exemplo recente da história constitucional brasileira, o poder constituinte (como potência) remonta aos movimentos ou as ações empreendidos pela sociedade civil brasileira e iniciados em 1985 e reaparece, como força, toda vez que se pretende atingir a constituição com golpes como a convocação de uma nova assembleia nacional constituinte ou com mutações constitucionais provocadas por quem não tem competência constitucional para tanto, como, por exemplo, o poder executivo (CHUEIRI; GODOY, 2010, p.165).

Portanto, trata-se de um sistema que se equilibra de forma a, por um lado, permitir a não estagnação democrática social e, de outro, impedir o sufocamento de direitos, especialmente pelas opiniões majoritárias constituídas de forma política. Gargarella (1996) dispõe ser um dos desafios da teoria do direito constitucional a compatibilização da Constituição - estável, positivada - com a intuição de um autogoverno, promovida pelo sentimento democrático. Aquela possui, em verdade, a proteção das liberdades, mas também o limite do poder arbitrário, impedindo que grupos padronizem condutas em nome do princípio majoritário.

Apresenta-se, assim, uma carga revolucionária interna ao próprio Estado Democrático, qual seja a capacidade de refundar as bases socialmente postas. Isso, porém, pode significar a superação de conquistas de minorias. Daí a importância da aplicação da Constituição, que assegura a concretização de direitos, permitindo a atualização da potência de transformação social presente no 
Covid-19 Desnuda As Contradições Da República Federativa Brasileira: A...

sentimento democrático. Fala-se, então, num Estado Democrático de Direito.

Dessa forma, agregando-se democracia e constitucionalismo, denota-se que as escolhas públicas deverão ser feitas de acordo com os preceitos definidos no mandamento constitucional, objetivando resultados que busquem a satisfação dos interesses sociais e não particulares ou de parte da sociedade, como espécie de soberano absoluto que desconsidera o sentimento coletivo, silenciando sujeitos de direitos. É o que ocorre, muitas vezes, pelas atitudes das autoridades eleitas, quando não governam para o povo.

Importante, nesse contexto, pensar também no direito à liberdade, mas não em sua mecânica formal-burguesa, e sim pelo ideal de igualdade/substancialidade. A necessidade de se garantir aos atores sociais a oportunidade equânime de participação e influência é fundamental para o bom exercício da democracia.

Para Dworkin (2002), a igualdade é o fundamento último da democracia e do constitucionalismo. Tomando por base o constitucionalismo como salvaguarda dos direitos postos e a democracia como vontade política majoritária, o direito à igualdade (art. $5^{\circ}$, caput, CF) é de fundamental importância prática, a fim de afirmar o próprio fundamento republicano brasileiro: a dignidade humana (art. $1^{\mathrm{o}}$, III, CF). Todo indivíduo deve ter a mesma oportunidade para intervir no sentimento democrático, de forma equânime (GARGARELLA, 2004).

Segundo Dworkin (2000), importantes liberdades morais auxiliam na concretização do direito fundamental à igualdade, e, para que assim ocorra, devem aquelas estar garantidas no texto constitucional, serem protegidas e efetivadas no seio social.

São liberdades fundamentais - expressão, religião, convicção etc. -, que decidem em favor da igualdade. Já outras liberdades, como a liberdade econômica, por exemplo, se apresentam de forma limitada pela atuação do poder público (CHUEIRI; FACHIN, 2006). Exemplos disso atualmente são as declarações do governo acerca de 
medicamentos que não possuem eficácia cientificamente comprovada no tratamento da Covid-19 (UOL, 2020), bem como discursos que não se correlacionam com as medidas sanitárias necessárias para proteção social, como o combate ao isolamento (UOL, 2020) e à utilização de máscaras (UOL, 2020).

Portanto, embora os direitos constitucionais não sejam absolutos, tendo limitações, algumas liberdades - como a econômica citada - são utilizadas como argumento para a defesa de discursos falsos, que não correspondem à veracidade científica, colocando em risco a sociedade e causando fraturas nas relações interpessoais a partir do mau exemplo dos gestores públicos.

Por igualdade, lembra-se do proposto por John Rawls (1971) acerca da garantia de que para que haja uma vida - digna, acrescento - para cada indivíduo, é necessário plena capacidade de fazer escolhas.

\footnotetext{
É a partir, sobretudo, da igualdade acima discutida (e/com liberdade) e da existência e fruição de instrumentos que facilitam e permitem atuações e decisões coletivas que se pode pensar em um processo transformador da realidade. Dessa forma, concebe-se a democracia como um processo orientado à transformação (CHUEIRI; GODOY, 2010, p. 169).
}

Carlos Santiago Nino (1989) propõe a ideia de democracia deliberativa5, qual seja a disseminação do conceito democrático, pautado pelo conflito, que faz surgir novas decisões de índole coletiva. Porém, há a necessidade de garantir a participação do povo no processo político. Assim, a democracia deliberativa busca rearticular os conceitos de soberania e poder constituinte, constitucionalismo e democracia, sem desmerecer o papel conflituoso das relações sociais,

5 Não se ignora, aqui, a possível distinção entre democracia participativa e democracia deliberativa. Para o presente artigo, ambas articulam a ideia contrária às decisões centralizadas do poder estatal, de forma a contribuir para maior influência dos cidadãos no debate e formação das políticas públicas. Para tanto, cita-se, como aprofundamento do estudo, as ideias de Habermas - teoria do agir comunicativo e, também, dissertação de Balestero, cujo título é $O$ Resgate da Democracia Participativa e Deliberativa como Mecanismo Legitimador do Exercício dos Poderes Estatais. 
que traz produção de novas ideias, a partir das tensões experimentadas pelas interações.

No presente estudo, busca-se, em conjunto com o fundamento da Constituição Federal de 1.988 da dignidade humana, compreender que a postura tomada pelo governo federal não condiz com o sentimento democrático - no momento, tenso e produtivo - e acaba por negar a participação de diversos atores políticos, o que contribui não só para o afastamento da política constitucional pátria, como também atua de forma contrária ao sentimento republicano.

A postura estatista e centralizada que reflete o cenário atual motivou desavenças entre as autoridades, e a população sofre pela confusão disseminada, especialmente em momento de medo diante da ameaça invisível da Covid-19. Trata-se da incorporação de uma agenda neoliberal e privatista, presente no discurso do Executivo Federal, que remonta ao estudo de Dardot e Laval (2016), ou seja, há uma presença forte do Estado - intervencionista - nas questões econômicas, que buscam assegurar as condições de competição, auxiliando o mercado e expandindo, por toda a sociedade, a ideologia competitiva, que provoca novas subjetivações, transformando as pessoas em empresários de si mesmos, alimentando a lógica da concorrência (SILVA, 2017).

Não apenas o Estado, mas toda a sociedade se adequa à nova racionalidade neoliberal, sob as premissas do mercado, traduzindo-se no homem competitivo, imerso no empreendedorismo de si mesmo. Tem-se, portanto, o neossujeito, a partir da governamentalidade estratégica, pautada em dispositivos de poder, buscando naturalizar a nova realidade do Estado-empresa. Produz-se, assim, uma sociedade esquizofrênica e doentia. (DARDOT; LAVAL, 2016; QUEIROZ, 2018).

Essa nova razão do mundo acaba por sufocar direitos e garantias sociais importantes para a proteção da dignidade humana, caracterizando a passagem do welfare to work (JESUS, 2018). Essa retórica pode ser confirmada pelas reportagens trazidas, demonstrando que a preocupação do chefe do Executivo federal é 
econômica, em detrimento da saúde dos brasileiros, reproduzindo o discurso neoliberal que sustenta as opções políticas em tempos de pandemia. Isso faz com que os direitos de liberdade sejam utilizados de forma arbitrária para o sustento dos interesses neoliberais e, dessa forma, a igualdade necessária para o tratamento dos cidadãos brasileiros não se concretiza no cotidiano, diante das forças homogeneizantes da racionalidade econômica (SANTOS, 2001).

Nesse sentido, recorrer ao Poder Judiciário é um caminho possível ${ }^{6}$, mas há limites procedimentais que demandam tempo, bem como limites interpretativo-decisórios que não permitem a ampliação do debate da forma como é cabível no campo estritamente político.

\section{JURISDIÇÃO CONSTITUCIONAL - A AUTORIZAÇÃO CONSTITUCIONAL E OS LIMITES DA DECISÃO}

Diante do quadro político que se apresenta no país nesse momento de crise, explicitado na introdução do presente artigo, abrese caminho para a judicialização das políticas públicas tomadas - e, também, pela omissão do Poder Público na tomada de tais medidas tendo em vista a proteção dos direitos humanos fundamentais da população, desnudando problemas estruturais de representação popular.

O Ministério da $\mathrm{Saúde}^{7}$ tomou as medidas consideradas necessárias pela OMS - em especial, o isolamento social já citado -

6 Dados buscados junto ao Painel de Ações Covid-19 junto ao STF: https://transparencia.stf.jus.br/single/?appid=615fc495-804d-409f-9bo8-

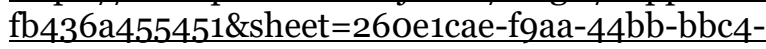
9d8b9f2244d $5 \&$ theme $=$ simplicity\&opt $=$ currsel\% 2 Cctxmenu\&select $=$ clearall, acesso em 08.04.2020.

7 Recomendações pelo Ministério da Saúde encontradas na cartilha disponível em: https://portalarquivos.saude.gov.br/images/pdf/2020/April/o6/CartilhaCoronaVamosNosProgeter-v10-0504-compactado-2.pdf, acesso em 08.04.2020. 
Covid-19 Desnuda As Contradições Da República Federativa Brasileira: A...

porém, o governo federal não é capaz de compreender-se internamente, nem externamente com os demais entes federativos, o que gera desconfiança e desinformação no tocante às medidas a serem tomadas no combate à pandemia. O chefe do Poder Executivo federal acabou por nomear um general das Forças Armadas para comandar a pasta da saúde para pôr fim às discussões tidas com os médicos que ocuparam anteriormente o cargo (FOLHA DE SÃO PAULO, 2020).

A compreensão não se dava, também, com os demais poderes constituídos, antes mesmo da crise da Covid-19 se instalar ${ }^{8}$. Nesse sentido, fala-se da jurisdição constitucional como alternativa de controle e contrapeso da harmonia dos poderes constituídos. Assim sendo, reforça-se a concepção de força normativa da Constituição, como argumentação suficiente para dar efetividade aos direitos consagrados no texto constitucional.

Trata-se, portanto, do

[...] constitucionalismo democrático que, assentado na valorização da constituição não somente como um documento, mas e acima de tudo por possuir um conteúdo de limitação de poder e de garantia de direitos, custodiando o seu êxito na defesa dos seus valores e fins pela jurisdição constitucional (NOBRE JÚNIOR, 2017, p.149).

Em consonância com o nas linhas iniciais, há o conflito entre constitucionalismo e democracia, que, ao mesmo tempo que é pautado pelos nortes da Constituição, esta também acaba por fomentar as tensões, de forma a produzir consensos e soluções democráticas, balanceando o princípio democrático - soberania popular - e direitos e garantias fundamentais - constitucionalismo. Nesta senda, "o controle da política passa a ser compartilhado, por assim dizer, por organismos não integrantes diretamente do núcleo estatal ao qual

\footnotetext{
8 A respeito dos desentendimentos entre os entes federativos, o Supremo Tribunal Federal se manifestou acerca da competência dos entes no tratamento das questões ligadas à pandemia: http://portal.stf.jus.br/noticias/verNoticiaDetalhe.asp?idConteudo=441447\&ori=1 , acesso em 11.05.2020.
} 
compete adotar as decisões políticas normais, cuja investidura não advém pela escolha popular (NOBRE JÚNIOR, 2017, p. 149).

No caso da crise motivada pelo Covid-19 no Brasil, diversas foram as medidas adotadas de forma a judicializar as políticas públicas adotadas pelo Governo Federal - sem desconsiderar, também, as posturas tomadas pelo Poder Legislativo Federal como resposta ou a medidas ineficazes do Executivo, ou pela inércia do Planalto. 9 É certo que para propiciar unidade de comportamentos e norte das medidas a serem tomadas pelo Estado brasileiro como um todo, caberá ao Poder Judiciário a interferência constitucional nas decisões políticas dos demais poderes. Nesse caso, a medida se faz com urgência e necessidade evidentes, diante da postura contraditória do poder político central da nação, que não encontra consenso sequer entre seus pares. ${ }^{10}$

Surge, assim, ponto nodal do constitucionalismo pátrio, qual seja a participação política de um órgão não legitimado pelo voto popular para decidir sobre questões fundamentais para o enfrentamento da crise instalada no país. Dessa forma, a atuação jurisdicional do Poder Judiciário no tocante a questões que envolvem políticas públicas, ainda que do âmbito dos poderes legitimados pelo voto popular - Legislativo e Executivo - não encontra óbice, desde que para salvaguardar os fundamentos da Constituição.

Isso significa que, para a proteção de direitos humanos fundamentais, há a possibilidade de apreciação pelo Poder Judiciário das decisões tomadas pelos demais Poderes da República.

Daí, então, é possível sustentar que, por atuar politicamente, a jurisdição constitucional visa ao bem estar geral, a ser concretizado mediante a incidência das diretrizes que a constituição delineou para a movimentação da atividade estatal e para o direcionamento do agir dos particulares. E assim o é

9 Como exemplo, cita-se o auxilio emergencial, de iniciativa do Poder Legislativo, aprovado pelas duas Casas e sancionado pelo Presidente da República: https://www.camara.leg.br/noticias/649910-conheca-as-regras-do-beneficioemergencial-de-r-600/, acesso em 08.04.2020.

10 Como exemplo, recente decisão do STF acerca da competência dos Estadosmembros em definir medidas para combate do Covid-19, acima citada. 
porque - e desde o princípio - o direito constitucional, em sua essência, diferencia-se dos demais ramos jurídicos (...) pela singularidade de que o fenômeno político é um dos seus elementos intrínsecos (NOBRE JÚNIOR, 2017, p.153).

Neste sentido, a própria Constituição de 1988 trouxe mecanismos que permitem a aproximação do Poder Judiciário em face dos demais poderes constituídos, ensejando análise constitucional acerca de questões políticas. Faz parte da jurisdição constitucional tal postura do Poder Judiciário, e isso já se encontra em andamento no momento de crise em que se encontra a República Federativa Brasileira, diante da razão neoliberal dos discursos do Poder Executivo federal. Nesse sentido, Bachof (1986, p.843):

\begin{abstract}
Considero indutable también, según mi propria experiencia como juez constitucional, que las reglas constitucionales no pueden ser interpretadas en muchos casos sin recurrir a valoraciones políticas; semejantes valoraciones políticas son empero siempre subjetivas hasta cierto grado. Por ello subsiste siempre e inevitablemente una relación de certa tensión entre derecho y política. El juez constitucional aplica ciertamente derecho. Pero la aplicación de este derecho implica necesariamente valoraciones políticas e cargo del juez que aplica la ley
\end{abstract}

Porém, há limites à atuação em comento, pois a postura judiciária não se dá de forma arbitrária, encontrando-se na atuação dos deveres constitucionais, em função típica de julgadores, conforme preceitua o art. 102 da CF. A atuação dos Poderes Políticos se dá diante da discricionariedade permitida pela democracia constitucional, norteadora dos interesses e objetivos sociais. Já a atuação do Poder Judiciário é vinculada, dando concretude aos valores previstos na Constituição, ainda que interpretando posições discricionárias dos demais poderes.

Há uma autocontenção - self restraint (Wolf, 1991) - que impera na força jurisdicional deste poder constituído. Como exemplo, cita-se a interpretação conforme a Constituição, modalidade de decisão judicial que busca, em último caso, a declaração de inconstitucionalidade de ato normativo, devendo o Poder Judiciário 
tomar as cautelas interpretativas necessárias para salvaguardar a norma produzida, sempre que possível (BARROSO, 2015, p.303-479). Da mesma forma, a Carta Magna previu instrumentos que buscam fornecer garantias à sociedade diante da inexistência de atitude dos poderes políticos, como o mandado de injunção (art. $5^{\circ}$, LXXI, CF e Lei 13.330/2016) e a ação direta de inconstitucionalidade por omissão (art. 103, $2^{\circ}$, CF e Lei 9.868/99). Há, portanto, autorização constitucional para que o Poder Judiciário provoque a manifestação dos demais poderes, uma vez que sua inércia acaba por ferir direitos humanos fundamentais, violando os desígnios constitucionais.

Conforme dispõe García (1984, p.538) "todo critério de oportunidad que refleja concepciones de 'política de Estado' inevitablemente 'se convierte' en um principio jurídico”, de forma que o juiz constitucional, na aplicação do direito, dá concretude ao conteúdo, delimitando-o e extraindo padrões normativos. Daí, a importância da coerência e da integridade das decisões (DWORKIN, 2007) pautadas em valores, mediante o critério da razoabilidade.

Voltando-se para o momento atual da crise provocada pelo Covid-19, e diante do desencontro de informações, há que buscar campo pacífico para nortear a sociedade diante do caos que se consumou. A Europa apresenta novos casos, caracterizando uma segunda onda da pandemia, que começa a alcançar o Brasil aos poucos, embora o Ministério da Saúde fale em consequências da primeira onda (FOLHA DE SÃO PAULO, 2020), e a economia apresenta lenta recuperação, podendo se estender pelos próximos anos (EL PAÍS, 2020).

Importante registrar que há recursos que não são utilizados pelo governo federal no combate à pandemia (CNTS, 2020), sem políticas públicas para aplicação, demonstrando mais uma vez a negação do governo federal em face das medidas necessárias para proteção social e enfrentamento da Covid-19, tendo em vista o sustento da narrativa de que a economia deve prosperar em detrimento do combate à pandemia, apoiando-se numa nova razão do mundo, qual seja a ótica neoliberal. 
[...] nas constituições recentemente promulgadas, o cariz analítico de suas disposições vem fazendo constar nestas, com assiduidade, balizas (guidelines) orientadoras de futura integração legislativa, reduzindo, assim, o espaço de liberdade do Parlamento, permitindo uma fiscalização pelo órgão judicial. Tal se afigura comum quanto ao reconhecimento dos direitos econômicos, sociais e culturais, ou de segunda dimensão. Entre nós, os exemplos são vários, conforme se pode vislumbrar no particular da saúde (arts. 196 a 198) (NOBRE JÚNIOR, 2017, p.155).

Desta feita, as questões pertinentes, inclusive dos direitos sociais, afetas à crise em comento, podem ser alçadas à Corte de Justiça para que esta delimite a atuação do Poder Executivo, de forma a evitar que a discricionariedade - e, até mesmo, arbitrariedade - do chefe de governo não apresente risco à população.

Ocorre que, no campo político, há sempre a possibilidade de maior participação da sociedade, de forma a garantir uma decisão que consista numa postura estatal mais condizente com os pilares do Estado brasileiro. Dessa forma, busca-se uma análise pluralística do direito e da política, de forma a propiciar campo social que amplia o debate e permite a consecução de decisões mais robustas acerca das medidas necessárias. Fala-se, aqui, do princípio e da instituição do comum, como alternativa para uma democracia absoluta (HARDT; NEGRI, 2004), de forma a proporcionar que a tomada de decisão se dê a partir das opções dos cidadãos, que cooperam entre si, a partir da cotidianidade (SANTOS, 2001).

Pelo exposto, verifica-se que recorrer ao Poder Judiciário é possível - em especial para conter arbitrariedades -, porém denota, ao menos, duas problemáticas: (i) a primeira diz respeito ao trâmites processuais, que demandam tempo necessário para formação do contraditório e ampla defesa, o que, em situações urgentes, pode significar prejuízo considerável à população, e (ii) a segunda diz respeito aos limites da interpretação e da decisão judicial, que devem correspondem a atuação jurisdicional do julgador, à luz da satisfação dos direitos humanos fundamentais, mas que, por não possuir margem ampla de escolha, acaba ficando refém dos autos, o que até 
permite a solução do processo, porém nem sempre com eficácia coletiva e esperada pela população.

É certo que, no momento atual, pensar na alteração estrutural do poder decisório pode não ser alternativa a ser posta em prática. Porém, o estudo acerca da melhor opção de representatividade da sociedade merece atenção, especialmente diante da situação de crise vivenciada, o que permite desnudar com maior clareza as dificuldades de consenso e escolha no sistema monista posto, deixando a população desprotegida pela negativa de direitos.

Passa-se a pensar, como alternativa, no pluralismo jurídicopolítico no âmbito da estrutura da sociedade pátria, a partir da instituição do comum ${ }^{11}$.

\section{PLURALISMO JURÍDICO-POLÍTICO: LEGITIMIDADE DEMOCRÁTICA DA DECISÃO. A REVITALIZAÇÃO SOCIAL A PARTIR DO COMUM}

Diante do quadro apresentado, e à luz dos conflitos decisórios que se desnudam entre os entes federativos e os poderes constituídos, fica clara a dificuldade de consenso permeada por fatores ideológicopolíticos. Trata-se da razão neoliberal presente no discurso do governo brasileiro.

É papel do Estado Democrático de Direito a valorização de fundamentos sociais e institucionais, por meio de políticas públicas que, para que estejam adequadas ao mandamus constitucional, devem ser orientadas pela redução das desigualdades sociais e regionais (art.

\footnotetext{
${ }^{11}$ Neste trabalho, tanto as ideias de Antonio Negri e Michael Hardt, quanto as de Pierre Dardot e Christian Laval são citadas, pois ambas apontam para a possibilidade de instituição do comum para uma nova democracia. Não se desconsidera que tais propostas apresentam pontos colidentes entre si, mas, para a temática aqui apresentada, o que merece destaque é a oportunidade de produção e instituição do comum para a tomada de decisão, de forma que ambas caminham em consonância nesse sentido. Ao final do terceiro tópico, apresenta-se uma proposta mais voltada às ideias de Dardot e Laval.
} 
$\left.3^{\circ}, \mathrm{CF}\right)$. O cenário atual demonstra que se faz necessário redefinir o processo decisório-normativo, com o fito de promoção do reconhecimento de novos sujeitos de direitos.

O arcabouço teórico que sustentou tanto os modelos estatais como a forma organizacional administrativa não atente mais as expectativas atuais justificando, assim, a busca por alternativas estruturais e inclusivas capazes de atender as relações sociais, mercadológicas e políticas a partir de sua complexidade e peculiaridades próprias da atualidade (ALVES, 2013, p.299).

Processo importante na reconfiguração do aspecto normativojurídico da sociedade é a revitalização social, ou seja, o resultado da ação estatal que busca concretizar políticas públicas para diminuição das desigualdades sociais, por meio da coprodução de necessidades sociais. Dessa forma, a necessidade de alteração do sistema normativo social é medida que busca o albergue de novos direitos, mas que, por conta do monismo jurídico, não é suficiente para a ampliação da diversidade sociocultural existente nas sociedades complexas contemporâneas, dificultando a tomada de decisão.

Destacam-se diversos grupos que, com a crise do Covid-19, sofrem consequências drásticas. Grupos marginalizados como os presos, indígenas, quilombolas, moradores de periferias e pessoas em situação de rua não possuem voz social, ou estão silenciados pela lógica neoliberal, embora devessem ser considerados pelas autoridades como sujeitos de direitos, e merecessem medidas para salvaguardar suas vidas. Alguns grupos possuem representações autônomas, mas outros contam, muitas vezes, apenas com o auxílio de ONGs e da própria comunidade, pelo exercício da alteridade e respeito para com o próximo, ensinando que a solidariedade é fruto da necessidade do convívio com o outro. ${ }^{12} \mathrm{O}$ não auxílio do Estado acaba sufocando as populações citadas, que, diante da necessidade de alimentação, não se ausentam dos trabalhos e expõem-se cada vez mais ao risco do contágio.

12 Ver a esse respeito: Subcidadania brasileira, de Jessé Souza. 
A cultura jurídica produzida ao longo dos séculos XVII e XVIII, na Europa Ocidental, resultou de um específico complexo de condições engendradas pela formação social burguesa, pelo desenvolvimento econômico capitalista, pela justificação do interesse liberal-individualista e por uma estrutura estatal centralizada. Certamente que este entendimento não só compartilha da ideia de que subsiste em cada período histórico uma prática jurídica dominante, como, sobretudo, confirma a concepção de que o Direito é sempre produto da vida organizada enquanto manifestação de relações sociais provenientes das necessidades humanas (WOLKMER, 1995, p.17).

O que ocorre é que o Estado, pelas estruturas de administração político-jurídicas, acaba por encontrar, no direito, o fundamento racional que norteia o que pode e o que não pode nas sociedades. Porém, essa estrutura - legitimada a partir do sistema de divisão de poderes - impõe uma organização social e política que concentra o monopólio normativo nas mãos do Estado. Há, nessa organização, forte presença dos ideais burgueses-capitalistas que deflagram uma igualdade formal e reproduz mecanismos de desigualdade. Ou seja, o direito positivado, abstrato e coercitivo funciona, na verdade, como dispositivo de poder (FOUCAULT, 2014), produzindo efeitos de verdade que acabam por sufocar sujeitos de direitos invisíveis aos olhos do Leviatã.

O Estado monista, centralizador e detentor do poder da produção normativa e estruturas ideológicas fundamentadas no positivismo como simbologia de uma segurança jurídica inexistente, cede lugar a um modelo organizacional que envolve a participação efetiva da sociedade, a democracia participativa quebrando o individualismo e reconhecendo os sujeitos coletivos como fomentadores de um direito comunitário e participativo (ALVES, 2013, p.302).

Trata-se, para Boaventura de Souza Santos (1998), de um novo marco caracterizado pela pós-modernidade. As transformações necessárias no campo do direito buscam a transição para um novo contexto sociocultural, importante para a salvaguarda de novos direitos. O intuito é promover a inclusão de novos seguimentos marginalizados socialmente, gerando libertação e emancipação de 
sujeitos historicamente oprimidos, injustiçados, excluídos (WOLKMER, 2001).

Para tanto, tem-se que a democracia participativa busca a inclusão de esferas não estatais além do sufrágio, implantando políticas públicas e auxiliando numa construção racional da própria identidade cultural que funda a sociedade e afirma a liberdade. Porém, o discurso neoliberal funda também subjetividades, atingindo o cotidiano das relações sociais, traduzindo na imposição da lógica da concorrência e do empresariado de si mesmo, de forma que se faz necessário pensar para além da postura de uma democracia participativa dentro do modelo neoliberal.

Dardot e Laval (2016, p. 390) dispõem que não se pode propor, atualmente, a "dar novo fôlego a sistemas decadentes, amparando a combalida democracia representativa com as escoras bambas da democracia participativa”. Isso, por sua vez, representaria o reforço do próprio pensar da razão do mundo neoliberal e dos dispositivos estratégicos e, por isso, propõem contraculturas para uma nova governamentalidade, retomando a necessidade de se pensar num governo de si para reconstruir o neossujeito (DARDOT; LAVAL, 2016, p.395), a partir do enfrentamento da racionalidade imposta atualmente, de forma vertical e que pretende-se homogênea (SANTOS, 2001). A invenção dessa nova forma de vida passa, necessariamente, pela invenção coletiva, com a multiplicação e intensificação das contracondutas de cooperação. (DARDOT; LAVAL, 2016, p.401).

O governo dos homens pode alinhar-se a outros horizontes, além daqueles da maximização do desempenho, da produção ilimitada, do controle generalizado. Ele pode sustentar-se num governo de si mesmo que leva a outras relações com os outros, além daquelas da concorrência entre "atores autoempreendedores". As práticas de "comunização" do saber, de assistência mútua, de trabalho cooperativo podem indicar os traços de uma outra razão do mundo. Não saberíamos designar melhor essa razão alternativa senão pela razão do comum. (DARDOT; LAVAL, 2016, p.402). 
Apresenta-se a instituição do comum, o princípio político que se efetiva na esfera coletiva. Propõem-se três dimensões distintas do comum que se articulam, quais sejam o princípio político, a práxis instituinte e o governo. Portanto, exige-se a participação coletiva como fundamento para uma coobrigação política, e também a necessidade de se estabelecer o comum nas esferas social, econômica e jurídica, numa reestruturação das instituições sociais atualmente neoliberais. Cria-se, assim, a empresa comum, uma instituição democrática que busca reorganizar a economia. (DARDOT; LAVAL, 2017). Trata-se da latência dos titulares do poder constituinte tratado no início, e permite a reconstrução social com base nos anseios sociais, chamados por Hardt e Negri (2004) de multidão, alternativa ao Império atual (HARDT; NEGRI, 2002).

Tem-se uma revolução que se apresenta como um processo democrático, plural, construído coletivamente e que se efetiva a partir da práxis instituinte, mantendo-se por meio de um governo democrático do comum. O Estado não fará parte do processo de revolução, diante do fato de estar subordinado à nova razão do mundo, qual seja a ótica neoliberal, que depende da intervenção estatal para satisfação de seus interesses. (DARDOT; LAVAL, 2017; QUEIROZ, 2020).

Portanto, a proposta do comum está baseada em nove proposições políticas, que, paulatinamente, sustentarão as conquistas políticas para efetivação do comum. Uma transformação social e da norma jurídica (proposições 1 e 2), como mudanças jurídico-sociais; a emancipação do trabalho, a criação da empresa comum e a associação entre produtores do comum (proposições 3, 4 e 5), predominando na economia; a efetivação de uma democracia social e a transformação de bens e serviços públicos em instituições do comum (proposições 6 e 7) vindo na sequência, ainda num plano interno; e, por fim, a instituição global da efetivação da lógica do comum, com uma federação mundial dos comuns (proposições 8 e 9), de forma a produzir mudanças na razão neoliberal que impera atualmente. (DARDOT; LAVAL, 2017, p.479-604). 
Tais propostas são apresentadas para buscar construir uma nova racionalidade - comum - que encontra ecos nas sociedades atuais por todo o mundo, inclusive no Brasil, a partir das manifestações que ocorreram na última década, servindo de sustento para uma revitalização social a partir do comum. As propostas encontram eco no pensamento de Milton Santos (2001) em sua apresentação de uma outra globalização possível. Trata-se da busca pela ética da alteridade, por meio da promoção da inclusão social e das práticas culturais.

Conforme destaca Bento (2003, p.64), existe uma “preocupação com a igualdade, a justiça social e a proteção àqueles mais vulneráveis, vale dizer, expostos às incertezas”, gerando a necessidade de ampliação do campo do debate e da formação de consensos para oitiva de diversas vozes, que formam a identidade cultural brasileira, e evitam que decisões centralizadas sejam tomadas, em detrimento das realidades ainda marginais, que merecem respeito, em face de sua dignidade humana (art. $1^{\mathrm{o}}, \mathrm{CF}$ ).

Uma alternativa é a promoção da revitalização social por uma política democrática que se preocupa com a conexão entre cidadãos e governos, oportunizando maior humanidade. $\mathrm{O}$ objetivo de desenvolvimento da revitalização é evitar o Estado Paralelo, com normativas próprias e que se colocam de forma tangente ao ordenamento pátrio. Portanto, descentralizar a tomada de decisão pública, permitindo a insurgência dos saberes (FOUCAULT, 2019, p.262-277) de novos espaços locais de exercício político e de cidadania, buscando-se a representação de diferentes sujeitos, a possibilidade de frutificação das diversas culturas e o bom exercício da democracia pela participação igualitária dos cidadãos.

É verdade que nos últimos anos, no Brasil, surgiram espaços que destacam uma lógica individualista, narcisista e egocêntrica e expõem características de retrocessos sociais, culturais e jurídicos a partir do substrato do discurso neoliberal que sustenta a radicalidade 
de posturas e a restrição de direitos, criando bolhas e causando fraturas sociais.

Por isso é importante a aposta da instituição do comum na sociedade como alternativa para superar a narrativa neoliberal de exclusão e homogeneização presente nas autoridades do governo, de forma a fazer nascer forças cotidianas, a partir do estranhamento vivido nos espaços comuns de cooperação, permitindo uma construção de baixo, de uma cultura e de relações sociais comprometidas com a existência humana (SANTOS, 2001). A preocupação trazida a partir da consolidação da nova razão do mundo - o neoliberalismo - e a possibilidade de superação e instituição de uma outra racionalidade, condizente com o coletivo - o comum - é medida salutar e pode auxiliar na abertura de novos espaços - contracondutas - e para a instituição de uma nova práxis, repercutindo nos âmbitos social, jurídico, econômico e cultural. (DARDOT; LAVAL, 2016).

[...] devemos opor, portanto, uma dupla recusa não menos específica: a recusa de se conduzir em relação a si mesmo como uma empresa de si e a recusa de se conduzir em relação aos outros de acordo com a norma da concorrência. Nisso, essa dupla recusa não está ligada a uma "desobediência passiva". Porque, se é verdade que a relação consigo da empresa de si determina imediata e diretamente certo tipo de relação com os outros (a concorrência generalizada), inversamente a recusa de funcionar como uma empresa de si, que é distanciamento de si mesmo e recusa do total autoengajamento na corrida ao bom desempenho, na prática só pode valer se forem estabelecidas, com relação aos outros, relações de cooperação, compartilhamento e comunhão. (DARDOT; LAVAL, 2016, p.400-401)

No momento atual da Covid-19, com diversidade de opiniões dos entes federativos e dos poderes constituídos, apostar na centralidade da decisão acaba por prejudicar o caminho conjunto ao norte da solução da crise ou, ainda, com a judicialização das questões políticas, que podem prejudicar a solução eficaz, uma vez que a tomada de decisão no âmbito jurídico encontra os limites apresentados anteriormente. Portanto, ainda que não altere a estrutura políticoadministrativa nesse momento de crise, a abertura do espaço público 
à sociedade é medida salutar no combate à crise instalada, evitando-se a centralidade da razão, sob pena de correr-se o risco da produção do chamado racismo de Estado (AGAMBEN, 2002; FOUCAULT, 2019).

Nesse sentido, Dardot e Laval (2016) propõem que a subjetivação individual está intimamente ligada à subjetivação coletiva, de forma que a inovação de contracondutas, ensejando novas formas de subjetividade, somente poderá ocorrer a partir da invenção coletiva, devido à cooperação possível. Dessa forma, "as práticas de 'comunização' do saber, de assistência mútua, de trabalho cooperativo podem indicar os traços de outra razão do mundo" (DARDOT; LAVAL, 2016, p.402), o que constituir-se-á numa razão do comum (DARDOT; LAVAL, 2017). Assim sendo, o pluralismo jurídico pode auxiliar na construção de uma nova proposta de revitalização social a partir da instituição do comum, em consonância com a proposta $n^{\circ} 2$ apresentada por Dardot e Laval.

de cunho comunitário-participativo no âmbito da revitalização social com o objetivo de demonstrar que, mesmo sem negar a intervenção estatal, é possível reconhecer sujeitos coletivos ou não construindo novos paradigmas jurídicos e administrativos que atendam melhor e de forma mais eficiente os problemas e conflitos sociais, propondo ações capazes de alterar o estão atual de exclusão e desigualdades (ALVES, 2013, p.307).

Segundo Wolkmer (2001, p.100), a abertura de "novos espaços institucionais periféricos passa, fundamentalmente, pela legitimidade instaurada por novos atores sociais, e pela justa satisfação de suas necessidades”. Assim, o pluralismo jurídico de cunho comunitário-participativo apresenta como objetivo - e desafio de instituição da nova razão do mundo, o comum - a construção de uma sociedade mais democrática, com o norte da coletividade, dos direitos humanos, da cidadania e da redução das desigualdades sociais, cumprindo, assim, com os mandamentos da Carta de 1988. 


\section{CONCLUSÃo}

Portanto, conclui-se que a estrutura do Estado brasileiro, fundada numa centralização política na tomada da decisão, não protege de forma suficiente os direitos dos cidadãos, de forma que estimular o centro decisório pluralista acaba por permitir maior desenvolvimento do Estado Democrático de Direito.

A confluência entre democracia e constitucionalismo permite a produção do consenso por meio da tensão entre a presença da soberania popular e a latência do poder constituinte. Há, assim, o desenvolvimento de novos direitos para novos sujeitos, ao mesmo tempo que o respeito e resguardo aos direitos postos, encontrando limite no norte axiológico-normativo da dignidade da pessoa humana.

O Poder Judiciário pode e deve ser chamado a atuar em momentos de crise política, em especial para conter arbitrariedades, decidindo acerca de questões amplas e que envolvem aspectos discricionários dos demais poderes constituídos. Porém, a atuação se dá pela jurisdição constitucional, que dispõe de limites procedimentais e decisórios, sob pena de se pautar o magistrado em poder arbitrário, não lhe conferido pela Constituição Federal de 1.988.

Há, no discurso do governo federal, a presença de uma nova razão do mundo, dependente do Estado, qual seja o neoliberalismo, que repercute no social e molda subjetividades. O pluralismo jurídico surge como alternativa diante da situação posta, a partir da possibilidade de instituição do comum. Ao se evidenciar a dificuldade da escolha das autoridades constituídas no sistema monista, verificouse que as decisões tomadas muitas vezes ou se afastam da realidade de diversos sujeitos de direitos, ou acabam privilegiando interesses que não condizem com o sentimento democrático-republicano norteador do Estado de Direito.

A democracia do comum, promovendo a inclusão de setores diversos da sociedade, propicia a ampliação do debate por meio de maior discricionariedade do campo político, o que permite uma 
decisão mais plural e igualitária e fomenta a eficácia de direitos humanos fundamentais.

Superar a crise da Covid-19 é o primeiro e mais importante direito que se avista, e o faremos por meio da salvaguarda das vidas e da dignidade humana, ante a todo e qualquer direito econômico pautado exclusivamente no capital e na mão invisível do mercado. Porém, que sirva a situação embaraçosa em que se encontra o governo atual para demonstrar para a sociedade em geral - e para os representantes, em particular - que apostar no sistema monista de centralidade de decisões não é um caminho salutar, pois não apresenta satisfação dos direitos plurais. A práxis do comum pode ser um caminho mais auspicioso para uma revitalização social da democracia pós-moderna.

Dessa forma, postula-se por uma nova estrutura, com ditames democrático-republicanos que satisfaçam as exigências de uma Constituição social-garantista. Temos, agora, nova oportunidade de olharmos para as decisões tomadas anteriormente, verificar o caminho de insucesso e corrigir as rotas, incentivando a alteridade e o solidarismo, características de um verdadeiro Estado Democrático de Direito.

Data de Submissão: 29/06/2020

Data de Aprovação: 15/12/2020

Processo de Avaliação: double blind peer review

Editor Geral: Jailton Macena de Araújo

Editor de Área: Jailton Macena de Araújo

Assistente Editorial: Tâmisa Rúbia Santos Do Nascimento Silva 


\section{REFERÊNCIAS}

AGAMBEN, Giorgio. Homo Sacer. O poder soberano e a vida nua I. [1995] Tradução de Henrique Burigo. Belo Horizonte: Editora UFMG, 2002.

ALVES, Elizete Lanzoni. A Administração Pública e a Revitalização Social sob a Ótica do Pluralismo Jurídico. Pluralismo Jurídico: Os Novos Caminhos da Contemporaneidade. Antonio Carlos Wolkmer, Francisco Q. Veras Neto, Ivone M. Lixa (orgs.) $-2^{\mathrm{a}}$ ed. São Paulo: Saraiva. 2013. p. 299-309

\section{BACHOF, Otto. Nuevas reflexiones sobre la jurisdicción} constitucional. Entre derecho y política. Boletin mexicano de derecho comparado, Ciudad del México, año XIX, n. 57, set/dez. 1986.

BARROSO, Luís Roberto. Curso de direito constitucional contemporâneo: os conceitos fundamentais e a construção do novo modelo/ Luís Roberto Barroso $-5^{\mathrm{a}}$ edição. São Paulo: Saraiva, 2015 .

BRASIL. [Constituição (1988)]. Constituição da República Federativa do Brasil: promulgada em 5 de outubro de 1988

BENTO, Leonardo Valles. Governança e governabilidade na reforma do Estado: entre a eficiência e a democratização. Barueri: Manole, 2003.

BODIN, J. [1576] 1992. On sovereignty. Cambridge: CUP.

CHUEIRI, Vera Karam de; GODOY, Miguel G. Constitucionalismo e Democracia - Soberania e Poder Constituinte. Revista Direito GV. São Paulo. 6[1] p. 159-174. Janeiro-Junho 2010.

CHUEIRI, Vera Karam de; FACHIN, Melina. Dworkin e a tentativa de um constitucionalismo Apaziguado. Revista Brasileira de Direito Constitucional, São Paulo, v.2, jan/jun. 2006

CNTS. Governo Bolsonaro não usa dinheiro aprovado para combate à pandemia. Confederação Nacional dos Trabalhadores da Saúde. Publicado em 25 de novembro de 2020. Disponível em Governo Bolsonaro não usa dinheiro aprovado para combate à pandemia | CNTS. Acesso em 30.11.2020.

DARDOT, Pierre; LAVAL, Christian. A nova razão do mundo: ensaio sobre a sociedade neoliberal / Pierre Dardot; Christian Laval; tradução Mariana Echalar. - 1. ed. - São Paulo : Boitempo, 2016. 
Covid-19 Desnuda As Contradições Da República Federativa Brasileira: A...

DARDOT, Pierre; LAVAL, Christian. Comum: ensaio sobre a revolução no século XXI / Pierre Dardot, Christian Laval; tradução Mariana Echalar. - 1. ed. - São Paulo : Boitempo, 2017.

DWORKIN, Ronald. O império do Direito. (Tradução de Jefferson Ruiz Camargo). 2. ed. São Paulo: Martins Fontes, 2007.

DWORKIN, Ronald. Levando os direitos a sério. Trad. Nelson Boeira. São Paulo: Martins Fontes, 2002.

DWORKIN, Ronald. Sovereign virtue: the Theory and practice of equality. Cambridge: Harvard University Press, 2000

EL PAÍS. FMI melhora previsão econômica para o Brasil em 2020, mas estima recuperação mais lenta. Internacional. EL PAÍS Brasil. Publicado em 13 de outubro de 2020, 10h16. Disponível em FMI melhora previsão econômica para o Brasil em 2020, mas estima recuperação mais lenta | Internacional | EL PAÍS Brasil (elpais.com). Acesso em 30.11.2020.

FOLHA DE SÃO PAULO. Bolsonaro decide efetivar Pazuello como ministro da Saúde. Publicação em 14 de setembro de 2020, 20ho6. Atualizado em 14 de setembro de 2020, 21h22. Disponível em Bolsonaro decide efetivar Pazuello como ministro da Saúde 14/09/2020 - Equilíbrio e Saúde - Folha (uol.com.br). Acesso em 30.11.2020.

FOLHA DE SÃO PAULO. Pazuello nega 'segunda onda' da Covid no Brasil e fala em 'repique' no Sudeste e Sul. Publicado em 26 de novembro de 2020, 21h24. Atualizado em 26 de novembro de 2020, 20h55. Disponível em Pazuello nega 'segunda onda' da Covid no Brasil e fala em 'repique' no Sudeste e Sul 26/11/2020 - Cotidiano - Folha (uol.com.br). acesso em 30.11.2020.

FOUCAULT, Michel. Microfísica do poder. Organização, introdução e revisão técnica de Roberto Machado. $9^{\mathrm{a}}$ edição. Rio de Janeiro/São Paulo. Paz e Terra. 2019.

FOUCAULT, Michel. Em defesa da sociedade: curso no Collège de France (1975-1976). Tradução Maria Ermantina Galvão. $2^{\mathrm{a}}$ ed. São Paulo. Editora WMF Martins Fontes. 2010 (Coleção obras de Michel Foucault).

FOUCAULT, Michel. História da sexualidade 1: A vontade de saber. Tradução Maria Thereza da Costa Albuquerque e J.A. Guilhon Albuquerque. $9^{\text {a }}$ edição. Rio de Janeiro/São Paulo. Paz e Terra. 2019 (Coleção Biblioteca de Filosofia). 
FOUCAULT, Michel. Vigiar e Punir: nascimento da prisão.

Tradução de Raquel Ramalhete. 42. ed. Petrópolis, Rio de Janeiro.

Vozes, 2014.

FOUCAULT, Michel. Dits et écrits (1954-1988). Paris: Gallimard, 2001. 2 V.

FOUCAULT, Michel. The history of sexuality: an introduction. New York: Vintage Books, v. 1. 1990.

GARCÍA, Enrique Alonso. La interpretación de la constitución. Madri: Centro de Estudos Constitucionais, 1984.

GARGARELA, Roberto. Constitución y democracia. In:

ALBANESE, Susana; et al. (Orgs) Derecho constitucional. Buenos Aires: Universidad, 2004.

GARGARELA, Roberto. La justicia frente al gobierno: sobre el carácter contramayoritario del poder judicial. Barcelona: Ariel, 1996.

\section{HABERMAS, Jürgen. Teoria do agir comunicativo 1:} racionalidade da ação e racionalização social. Tradução Paulo Astor Soethe; revisão da tradução Flávio Beno Siebeneichler. São Paulo: Editora WMF Martins Fontes, 2012.

HABERMAS, Jürgen. Teoria do agir comunicativo 2: sobre a crítica da razão funcionalista. Tradução Flávio Beno Siebeneichler. São Paulo: Editora WMF Martins Fontes, 2012.

HARDT, Michael; NEGRI, Antonio. Império. Trad. Berilo Vargas. 4. ed. Rio de Janeiro: Record, 2002.

HARDT, Michael; NEGRI, Antonio. Multitude: war and democracy in the age of empire. New York: Penguin, 2004.

JESUS, Cristian Arão Silva de. A nova razão do mundo: ensaio sobre a sociedade neoliberal [Pierre Dardot e Christian Laval]. Miolo, revista crítica marxista, p. 213-215, 2018.

KALYVAS, Andreas. Democracia Constituinte. Lua Nova, São Paulo, 89. pg. 37-84. 2013.

LEFORT, Claude. A invenção democrática - os limites do totalitarismo. São Paulo: Brasiliense, 1981.

NEGRI, Antonio. O poder constituinte - ensaio sobre as alternativas da modernidade. Trad. Adriano Pilatti. Rio de Janeiro: DP\&A, 2002. 
Covid-19 Desnuda As Contradições Da República Federativa Brasileira: A...

NINO, Carlos Santiago. Ética y derechos humanos: um ensayo de fundamentación. Madrid: Ariel, 1989.

NINO, Carlos Santiago. La constitución de la democracia deliberativa. Barcelona: Gedisa, 2003.

NOBRE JÚNIOR, Edilson Pereira. Jurisdição Constitucional e Política. Revista de Investigações Constitucionais. Curitiba. Volume 4, n. 2, p. 147-162. Maio/Agosto. 2017.

QUEIROZ, Felipe. A nova razão do mundo: ensaio sobre a sociedade neoliberal. Resenha. Caderno CRH, Salvador, v. 31, n. 82, p.187-191, Jan./Abr. 2018.

QUEIROZ, Felipe. A revolução do comum. Resenha Book Review. Trabalho, educação e saúde, Rio de Janeiro, 2020.

RAWLS, John. A theory of justice. Cambridge: Harvard University Press, 1971.

SANTOS, Milton. Por uma outra globalização: do pensamento único à consciência universal / Milton Santos - $6^{\mathrm{a}}$ edição. Rio de Janeiro: Record, 2001.

SOUZA SANTOS, Boaventura de. Pela Mão de Alice: O Social e o Político na Pós-Modernidade. 3. ed. Porto: Editora Cortês, 1998.

SIEYÉS, Emmanuel Joseph. A constituinte burguesa - que é o Terceiro Estado? Trad. Norma Azeredo. 3. ed. Rio de Janeiro: Luman Juris, 1997 (Clássicos do direito).

SILVA, Thiago Dias da. A nova razão do mundo: ensaio sobre o neoliberalismo. Resenha de Pierre Dardot e Christian Laval. São Paulo: Boitempo, 2016. Cognitio Estudos. Revista Eletrônica de Filosofia. Vol. 14, $\mathrm{n}^{\mathrm{O}} 2$, julho-dezembro, 2017.

UOL. Bolsonaro volta a defender cloroquina contra covid-19 e diz que desemprego leva à morte. Publicação em 13.08.2020, 12ho5. Disponível em Bolsonaro volta a defender cloroquina contra covid-19 e diz que desemprego leva à morte (uol.com.br). Acesso em 30.11.2020.

UOL. Coronavírus: Bolsonaro volta a criticar isolamento social e diz que não dá para continuar assim. Publicação em 26.05.2020, 22ho8. Disponível em Coronavírus: Bolsonaro volta a criticar isolamento social e diz que não dá para continuar assim (uol.com.br). Acesso em 30.11.2020

UOL. Bolsonaro diz que máscara tem "eficácia quase nula"; ciência aponta proteção. Publicação em 19.08.2020, 22 h24. 
Disponível em Bolsonaro diz que máscara tem "eficácia quase nula"; ciência aponta proteção (uol.com.br). Acesso em 30.11.2020.

WOLF, Christofher. La transformación de la interpretación constitucional. Trad. Maria Garcia Rubio de Casas y Sonsoles Valcárel. Madrid: Civitas, 1991.

WOLKMER, Antonio Carlos. Ideologia, Estado e Direito. 2. ed. São Paulo: Revista dos Tribunais, 1995.

WOLKMER, Antonio Carlos. Pluralismo Jurídico:

Fundamentos de uma nova cultura no Direito. 3. ed. São Paulo: Alfa-Omega, 2001

WOLKMER, Antonio Carlos. Pluralismo Jurídico: fundamentos de uma nova cultura do direito/Antonio Carlos Wolkmer. $4^{\mathrm{a}}$ ed., rev. e atual. São Paulo, Saraiva. 2015. 


\title{
Covid-19 Denuded The Contradictions Of The Brazilian Federative Republic: The Difficulty of Legitimizing Decision-Making And The Proposal of The Institution Of The Common
}

\author{
Gabriel Scudeller de Souza
}

Vivianne Rigoldi

\begin{abstract}
The world, in 2020, was added by a new coronavirus that spread to several countries and brought health problems, including deaths. The pandemic was decreed. The high contamination is the problem, given the fact of collapsing health systems. The main measure defended is social isolation, in order to flatten the contagion curve. In Brazil, federal entities do not defend the same proposals, and contribute to the worsening of the crisis. It is demonstrated that the difficulty of the national system in dealing with the crisis bares the problem of decision-making. In this scenario, it is thought to turn to the judiciary to assess the defense of fundamental human rights in the face of state public policies. It happens that the judicial process, although an alternative, requires respect for procedural procedures, which may not be efficient for an urgent decision. Thus, in view of the teachings about legal pluralism, as well as in the light of a more participatory and deliberative system, a new decision-making, non-centralizing and more democratic center is postulated, identified as a principle of the common. By the deductive method, with bibliographic consultations and scientific articles, we seek to understand such social issues, now bare in front of Covid-19.
\end{abstract}

Keywords: Legal pluralism. Decision-making. Pandemic. Covid-19. Common.

DOI: https://doi.org/10.22478/ufpb.1678-2593.2021v20n43.53647

Conteúdo sob licença Creative Commons: Attribuition-NonCommercial-NoDerivative 4.0 International (CC BY-NC-ND 4.0)

(cc) BY-NC-ND 